F. med. Genet. (1968). 5, 134.

\title{
Mental Retardation in a Child with a Long B-group Chromosome
}

\author{
BLUMA TISCHLER, MARGARET J. COREY and PACITA CO-TE
}

\begin{abstract}
From The Woodlands School, New Westminster, B.C.; and the Division of Medical Genetics, Department of Paediatrics, University of British Columbia, Vancouver, Canada
\end{abstract}

A long unpaired B-group chromosome has been described in 12 reports (Edwards et al., 1962; Gagnon et al., 1963; Bray and Ann Josephine, 1964; Court Brown et al., 1964; Wallace and Anderson, 1964; Makino, Aya, and Sasaki, 1965; Mann et al., 1965; Gendel and Wasserman, 1966; Trujillo et al., 1966; Hsu et al., 1967; Shaw, Cohen, and Hildebrant, 1965; Atkins and Feingold, 1967). In all but one of these (Shaw et al., 1965) the excessive length is attributed to the addition of chromosomal material to the long arm, but there appears to be little phenotypic resemblance among them.

Since it is possible that as more cases are reported distinct phenotypes will emerge, we would like to report another case of a child with a long B-group chromosome.

\section{Case Report}

The patient, a boy born May 18, 1962, is one of four children born to an unmarried mother. At the time of birth the mother was 27 years of age. No physical or mental abnormalities were evident in either parent and the other three children were reported to be developing normally.

The pregnancy was unremarkable except that the mother had influenza in the last month of gestation. The labour lasted 48 hours, but delivery was spontaneous. The birthweight was $2380 \mathrm{~g}$. $(5 \mathrm{lb} .4 \mathrm{oz}$.). There were some breathing difficulties immediately after delivery, and he was kept in an incubator for about two weeks. Twitching was reported in the neonatal period. There were feeding difficulties and vomiting in the first few years of life. At $2 \frac{1}{2}$ months he had a grand mal seizure, and a total of 16 seizures have been reported.

Physical Examination. Photographs of the patient are presented in Fig. 1a and $b$. His height at $4 \frac{1}{2}$ years was $94 \mathrm{~cm}$. (37 in.), weight $10.4 \mathrm{~kg}$. (23 lb.), and head circumference $46 \mathrm{~cm}$. (18 in.). His height was significantly small for his age and his weight was also sig-

Received May 8, 1967. nificantly low for his height. His head circumference was significantly small for his height; his skull showed slight asymmetry with the left occipital region being more prominent. A yellowish tint of the skin was noted, which was more conspicuous at the neck and the palm regions. The sclera were of normal colour. A number of physical anomalies were noted, including antimongoloid slant of the eyes, epicanthic folds, hypertelorism, high narrow palate, widely spaced incisors, with malalignment of the two upper incisors and an overbite. His eyelashes were long, and moderate ptosis was noted. The nose was beak shaped. The right earlobe was somewhat larger than the left and the ear canals were narrow. The testes were undescended.

On the Griffith's mental developmental scale his mental age was 4 months. On the Vineland Social Maturity Scale his social age was estimated to be 6 months.

Skull $x$-ray films revealed some degree of plagiocephaly. Bone age corresponded to his chronological age. General urine examination showed no abnormalities. Paper chromatography of urine revealed a normal amino acid pattern. Fasting blood sugar, urea nigrogen, calcium, phosphorus, alkaline phosphatase, protein-bound iodine, and vitamin A were within normal limits. The carotene levels were raised $(453 \mu \mathrm{g}$./ $100 \mathrm{ml}$.). Raised carotene levels are known to occur in severely retarded individuals; however, the cause of it is not well understood (Hirsch and Fisher, 1955, and personal observation of one of the author's (B.T.)). The yellowish tint of the skin in our case can probably be explained by the raised carotene levels.

The electroencephalogram was thought to be within normal limits for his age.

Chromosome Studies. Chromosome preparations were made from cultured peripheral blood cells using a micro-culture technique. All 33 well-spread metaphases examined contained 46 chromosomes, and a long atypical chromosome could be recognized in each cell. The karyotype analysis (Fig. 2) revealed only three B-group chromosomes and a long unpaired chromosome, with short arms similar in length to the short arms of the B-group chromosome, but with long arms considerably 134 


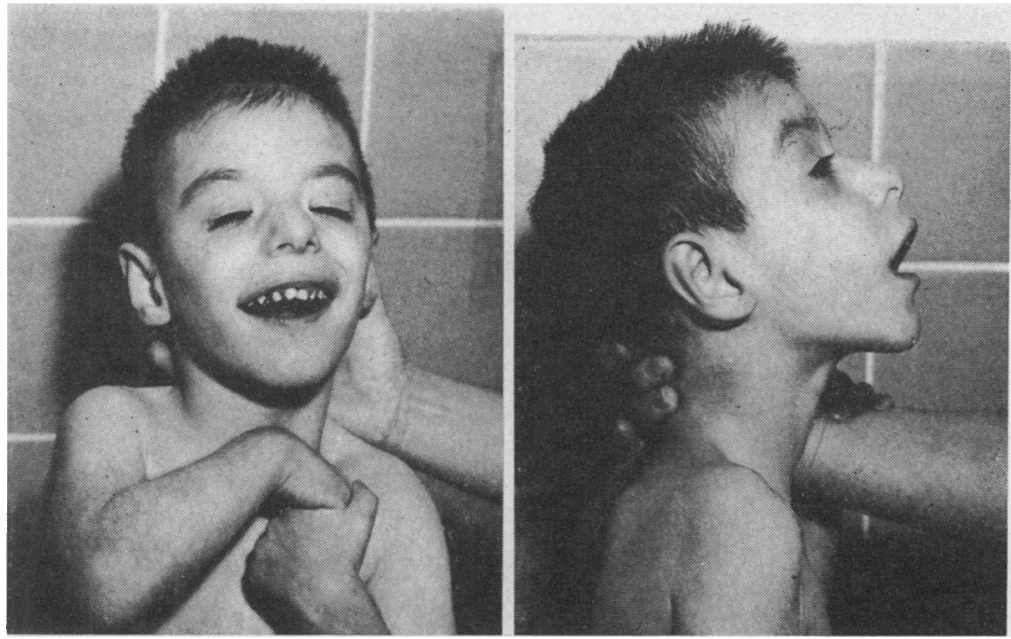

FIG. 1a and $b$. The patient.

giving it a total length of slightly greater than chromosome pair 1.

Chromosome analysis of the mother revealed a normal female karyotype. Since the patient is illegitimate and the whereabouts of the putative father unknown, karyotypes of the father could not be obtained. As there are no full sibs and the mother's karyotype is normal, no attempt was made to study her other children.

Dermatoglyphs. There was a single palmar crease bilaterally. The axial triradii were displaced distally (L: $50 \%$, atd $123^{\circ} ; \mathrm{R}: 53 \%$, atd $82^{\circ}$ ). There were no patterns in the hypothenar or thenar + Int ${ }_{1}$ area. There was a distal loop pattern in Int $_{4}$ bilaterally.

The digital formula was ( $\mathrm{L}: 5-1, \mathrm{R}: 1-5$; ridge counts in brackets) $\mathrm{U}(7), \mathrm{U}(5), \mathrm{A}(0), \mathrm{A}(0), \mathrm{U}(9), \mathrm{U}(15), \mathrm{A}(0)$, $U(1), U(6), W(27)$. The ridge count of 70 is significantly reduced from the normal male average of $133.9 \pm$ 1.6 (unpublished data).

The dermal patterns on the feet were unremarkable. There was a large loop distal in the first interdigital area bilaterally. 


\section{Discussion}

Shaw et al. (1965) have suggested that a specific distal segment of a B-group chromosome is particularly vulnerable to breakage and exchange because of its heterochromatic nature. This suggestion is supported by the observation of a high frequency of chemically induced breakage in cultured cells (Shaw and Cohen, 1965), as well as reports of 11 unrelated families in which the karyotype of at least one individual indicates that this site has been involved in a translocation.

In the present instance the abnormal B chromosome could result either from a translocation in which chromosome material from an unidentified source has been translocated onto the long arm of a B group chromosome; or from an unequal chromatid exchange resulting in two daughter $\mathbf{B}$ chromosomes of unequal length. This could have taken place during parental gametogenesis, or in a very early cleavage division of the zygote.

The origin of the translocation material has been cytologically established in 5 of the 11 cases by a balanced translocation in the karyotype of the patient or one of the parents. In each case a different donor chromosome appears to be involved. When balanced translocations cannot be demonstrated, clinical similarity to known trisomy syndromes has been considered as evidence for the origin of partial trisomy. The usefulness of clinical criteria in establishing partial trisomy is limited not only by the fact that only three definitive syndromes have been established, but also because many of the characteristics appear to be common to most autosomal aberrations. To date, patients with long B chromosomes have shown a striking lack of clinical similarity, indicating that still other chromosomes may be involved in the translocation and are present in a partial trisomic state.

In the patient reported in this study cytological evidence for the origin of the excess chromosome material could not be demonstrated and the patient showed little phenotypic similarity to known trisomy syndromes. Of the other patients with long B-chromosomes this boy does have several points of similarity with the two patients described by Edwards et al. (1962), including short stature, skull asymmetry, and unequal size of the ears, narrow ear canal, beak-like nose, high narrow palate, and hypertelorism. Absence of congenital heart anomalies has been noted in all three patients, and a yellow skin colouring was noted in our patient and in the older patient described by Edwards et al. With the exception of single palmar creases and low ridge counts, there was little similarity of dermal pattern between Edwards' patients and the patient presented here.

\section{Summary}

Cytogenetic investigation of a mentally retarded child with multiple physical anomalies and abnormal dermatoglyphs has revealed an aberrant Bgroup chromosome with a disproportionately long long arm. The origin of the excessive material could not be established.

We wish to thank Dr. James R. Miller and Mrs. Joan Baillie for analysis of the dermatoglyphs and Miss Joyce Flood and Mrs. Joyce Sandercock for assistance with the chromosome preparations.

\section{REFERENCES}

Atkins, L., and Feingold, M. (1967). Enlarged B-group chromosome (4-5). Amer. F. Dis. Child., 113, 277.

Bray, P. F., and Ann Josephine, Sister (1964). Partial autosomal trisomy and translocation. F. Amer. med. Ass., 187, 566.

Court Brown, W. M., Mantle, D. J., Buckton, K. E., and Tough, I. M. (1964). Fertility in an XY/XXY male married to a translocation heterozygote. F. med. Genet., 1, 35.

Edwards, J. H., Fraccaro, M., Davies, P., and Young, R. B. (1962). Structural heterozygosis in man: analysis of two families. Ann. hum. Genet., 26, 163.

Gagnon, J., Archambault, L., Laberge, E., and Katyk-Longtin, N. (1963). Trisomie partielle 18 par insertion ou translocation $4 / 18$. Un. méd. Can., 92, 311

Gendel, E., and Wasserman, E. (1966). An asymmetric chromosome pair in group 4-5. Amer. F. Dis. Child., 111, 90.

Hirsch, W., and Fisher, J. (1955). Chemical examinations of the blood in mentally retarded children. Harefuah, 48, 27.

Hsu, L. Y. F., Nemhauser, I., Bettman, H. K., and Sobel, E. H. (1967). Mosaicism of an abnormally long B-chromosome in a boy with physical and mental retardation. Pediatrics, 39, 68 .

Makino, S., Aya, T., and Sasaki, M. (1965). A preliminary note on a familial $\mathrm{B} / \mathrm{C}$ chromosome translocation with regard to the spontaneous abortion. Proc. Fap. Acad., 41, 746.

Mann, J. D., Valdmanis, A., Capps, S. C., and Puite, R. H. (1965) A case of primary amenorrhea with a translocation of groups $B$ and C. Amer. F. hum. Genet., 17, 377.

Shaw, M. W., and Cohen, M. M. (1965). Chromosome exchanges in human leukocytes induced by mitomycin C. Genetics, 51, 181 . ,-- , and Hildebrant, H. M. (1965). A familial 4/5 reciprocal translocation resulting in partial trisomy-B. Amer. $\mathcal{f}$. hum. Genet., 17, 54.

Trujillo, J. M., Zeller, R. S., Plessala, R. A., and List-Young, B. (1966). Translocation heterozygosis in man. ibid., 18, 215.

Wallace, C., and Anderson, I. F. (1964). Group B/D translocation chromosome in case with stigmata of the D-trisomy. S. Afr. med. f., 38, 352. 